Research Article

\title{
Comparative Study on Thermos-Hydraulic Performance of Different Cross Section Shapes of Microchannels with Supercritical $\mathrm{CO}_{2}$ Fluid
}

\author{
Yi Tu $\mathbb{D}^{1}$ and Yu Zeng $\mathbb{D}^{2}$ \\ ${ }^{1}$ School of Mechanical Engineering, Hunan University of Arts and Science, Changde 415000, Hunan, China \\ ${ }^{2}$ School of Aeronautic Science and Engineering, Beihang University, Beijing 100191, China \\ Correspondence should be addressed to Yu Zeng; zengyu@buaa.edu.cn
}

Received 22 January 2021; Revised 15 July 2021; Accepted 26 July 2021; Published 6 August 2021

Academic Editor: Yuanyuan Duan

Copyright (C) 2021 Yi Tu and Yu Zeng. This is an open access article distributed under the Creative Commons Attribution License, which permits unrestricted use, distribution, and reproduction in any medium, provided the original work is properly cited.

The influence of the cross section shape of microchannels on the thermos-hydraulic performance of the supercritical $\mathrm{CO}_{2}$ fluid is an important issue in the design of industrial compact heat exchangers, but few studies have been conducted about this issue. In this paper, comparative studies of the flow and heat transfer performance of $\mathrm{SCO}_{2}$ fluid in horizontal microchannels with circular, semicircular, rectangle, and trapezoidal cross sections were conducted numerically. The comparison is based on the same hydraulic diameter and length for all channel types and is carried out under the same mass flux, outlet pressure, and wall heat flux. The fluid bulk temperature in this analysis ranges from $285 \mathrm{~K}$ to $375 \mathrm{~K}$, which covers the pseudocritical point of $\mathrm{SCO}_{2}$. The results show that the circular channel has the highest average heat convection coefficient, while the trapezoidal channel has the worst convective heat transfer performance under the same hydraulic diameter and boundary conditions. The results also indicate that the effect of cross section shape on the heat convection coefficient is significantly greater than that on the channel pressure drop, and the existence of the corner region in the cross section, especially the acute angle, will weaken the heat transfer performance.

\section{Introduction}

High-efficiency and compact printed circuit heat exchangers (PCHEs) use the same technique as for manufacturing printed circuit boards in the electronics industry. Microchannels are photochemically etched on the heat transfer surface. The etched-out plates are alternately joined by diffusion bonding and result in compact, extremely strong, all-metal heat exchanger cores [1]. Through these processing technologies, PCHE can operate in extreme environments (temperature higher than $900^{\circ} \mathrm{C}$ and pressure higher than $60 \mathrm{MPa}$ ), which makes it have broad application prospects in the field of industrial energy [2]. Carbon dioxide $\left(\mathrm{CO}_{2}\right)$ is a nontoxic, nonflammable, and inexpensive natural refrigerant that can be used as a heat transfer medium in compact heat exchangers. It has many favorable characteristics when it is in supercritical state, such as high density, low viscosity, and high thermal conductivity, as shown in Figure 1, which makes supercritical $\mathrm{CO}_{2}\left(\mathrm{SCO}_{2}\right)$ become the most important candidate working medium in the future compact energy systems [3-5]. The application of PCHE has attracted the attention of many design engineers and research laboratories involved in power conversion cycle studies, especially in $\mathrm{SCO}_{2}$ Brayton cycle development [6], and one of the most concerned factors for designers is the flow and heat transfer performance of $\mathrm{SCO}_{2}$ fluid in different types of channels of PCHE.

In [7], the heat transfer and pressure drop characteristics of zigzag channel PCHE with semicircular cross section in a $\mathrm{SCO}_{2}$ experimental loop were studied and empirical correlations were proposed to predict the local heat convection coefficient and pressure drop factor for the tested PCHE. In [8], an experimental study was performed on the thermalhydraulic characteristics of microchannel heat exchangers with S-shaped and zigzag fins in a $\mathrm{SCO}_{2}$ loop and an empirical correlation of the Nusselt number and pressure drop 


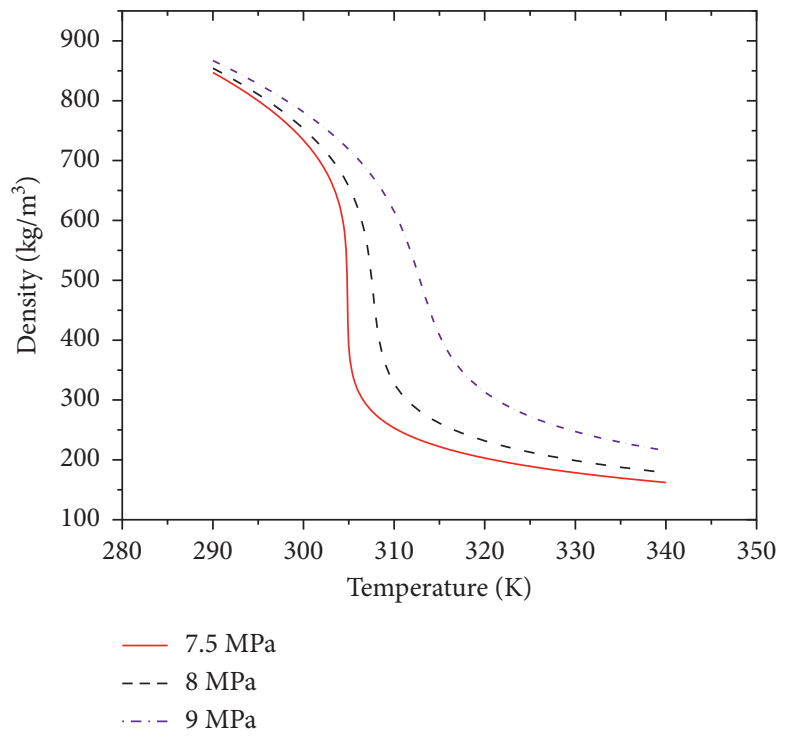

(a)

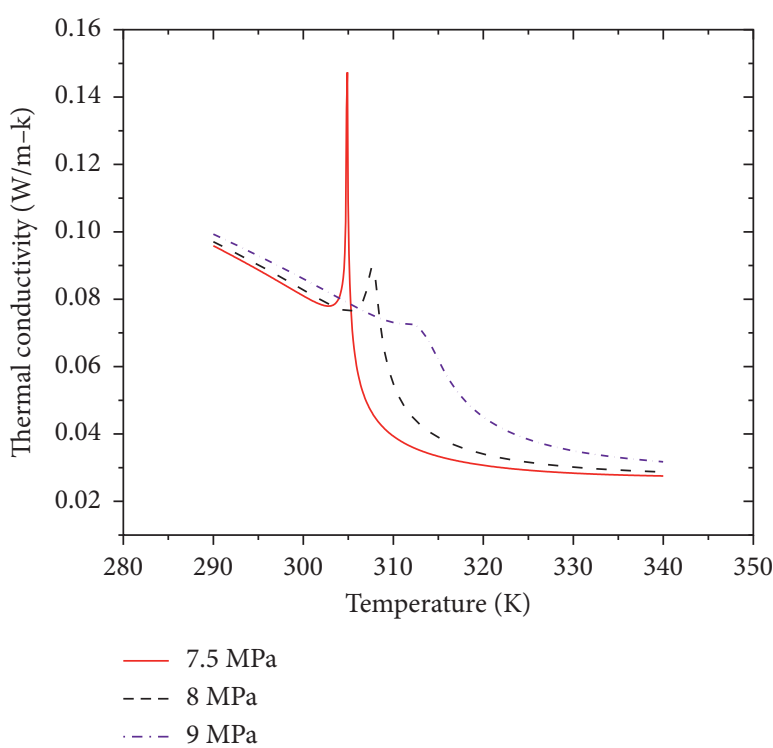

(c)

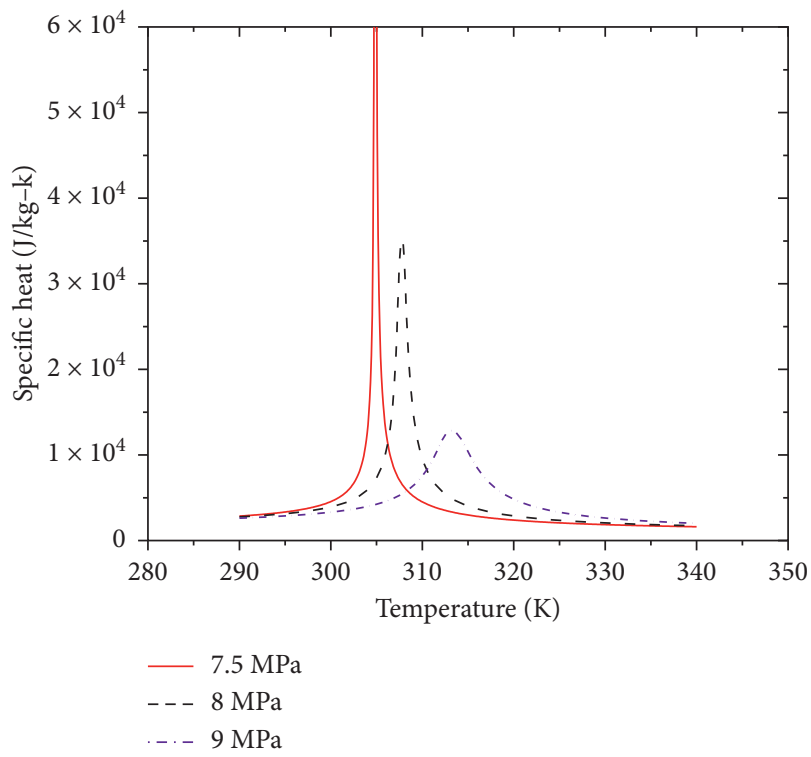

(b)

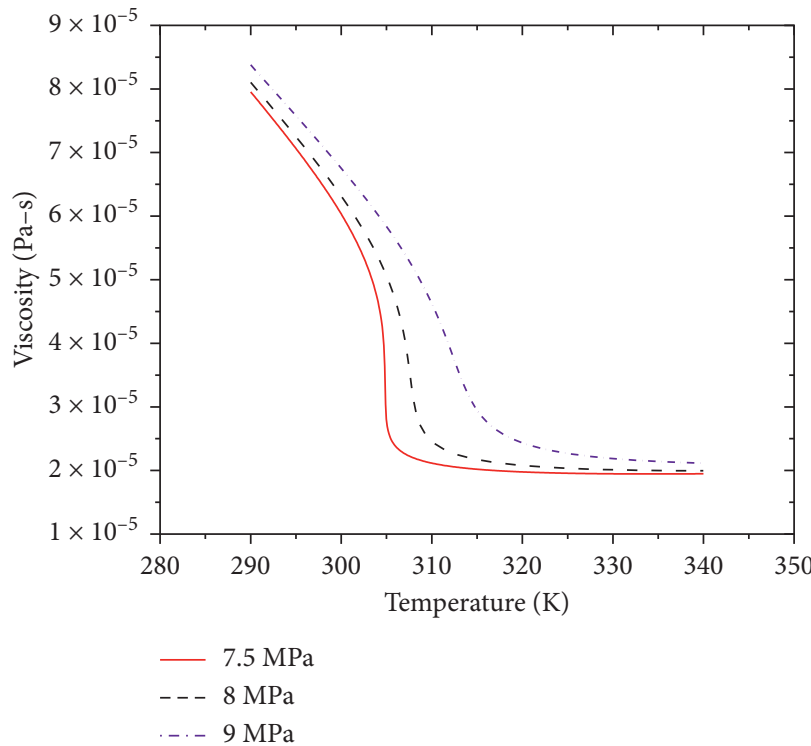

(d)

FIGURE 1: Thermophysical properties of $\mathrm{CO}_{2}$ at 7.5, 8.0, and $9 \mathrm{MPa}$ (a) density; (b) specific heat; (c) thermal conductivity; and (d) dynamic viscosity.

factors was proposed. In [9], numerical simulations of microchannel heat exchangers were carried out to evaluate the effect of the shape of channels on the performance of the heat exchangers with the same cross section. In $[10,11]$, the forced convection heat transfer of $\mathrm{SCO}_{2}$ flowing through straight semicircular channels was investigated numerically and experimentally, and correlations were developed to predict the heat transfer characteristics. In [12], comparative studies of PCHE were performed with various channel cross section shapes and zigzag channel configurations. The research results show that the rectangular channel has the best thermal performance but the worst hydraulic performance. In [13], the thermal performance of wavy-channeled PCHEs with semicircular section and the effects of waviness factors were studied. In [14], the local heat transfer characteristics of $\mathrm{SCO}_{2}$ flowing in the horizontal semicircular straight channel of the PCHE during cooling condition were investigated numerically, and it was found that the convection heat transfer of $\mathrm{SCO}_{2}$ is enhanced at the top position due to the buoyancy effect and is weakened at the corner position due to the structural effect. In $[15,16]$, the flow and heat transfer characteristics of $\mathrm{SCO}_{2}$ in both circular and semicircular horizontal channels of the cooling process were studied, and it was found that the circular channel has better thermal performance than the semicircular channel at the same hydraulic diameter and internal flow velocity. 
Although etching semicircular channels on PCHE plates is expedient in the processing approach for certain instances, other shaped passages are also possible achieved by chemical etching [17]. However, most of the existing research on the flow and thermal performance of PCHE is carried out based on semicircular cross section channels. There are few studies on other channel types such as rectangular and trapezoid. Compared with semicircular channels, the advantages or disadvantages of other channel cross section types in terms of flow and heat transfer performance are also essential for engineer design. CFD analysis is an important method to study fluid heat transfer and hydraulic performance besides experiment, especially suitable for the research work that needs to carry out a large number of analysis conditions [18] [19-21]. This paper studies the thermal-hydraulic performance of $\mathrm{SCO}_{2}$ flowing in different cross section shaped microchannels numerically, which can provide references for the industrial design of microchannel heat exchangers such as PCHE.

\section{Numerical Methodology}

This numerical simulation of the microchannels uses $\mathrm{SCO}_{2}$ as the fluid medium, and there are two key factors which need to be focused on: one is the drastic variation of physical properties near the pseudocritical point, and the other is the flow and thermal characteristics induced by the channel section shapes.

2.1. Mesh Description and Independency. Four different cross section shapes of micro-straight channels with the same hydraulic diameter are adopted in this study. The definition of section geometric parameters is shown in Figure 2, and the length of all passages is $200 \mathrm{~mm}$. Structure meshes of the analysis domains were generated using ANSYS ICEM 19.2. The cross-sectional meshes are shown in Figure 2, and the mesh along the length of the pipe is shown in Figure 3.

Figure 3 also shows the boundary conditions in this study. In our simulation, the outlet pressure $P_{\text {out }}$ was set to $8 \mathrm{MPa}$ and the inlet fluid temperature $T_{\text {in }}$ changes in a certain range $(290 \mathrm{~K}$ to $350 \mathrm{~K})$ to make the fluid bulk temperature cover the critical point. Constant heat flux boundary is applied to the wall with $\pm 12 \mathrm{~kW} / \mathrm{m}^{2}$ for the heating and cooling case. Also, the inlet mass flow rates are set to $200 \mathrm{~kg} / \mathrm{m}^{2}-\mathrm{s}$.

Steady-state simulations were carried out using ANSYS FLUENT 2019. An NIST Real Gas model with the REFPROP v9.1 database was used to evaluate thermodynamic and transport properties of approximately of $\mathrm{CO}_{2}$. An SST $\mathrm{k}$-omega model is opted for modeling turbulence. This model combines the advantages of the k-epsilon and k-omega models using blending functions. The k-omega model was activated in the near-wall region, and the k-epsilon model was used in the region far from the wall. Pressure-based coupled algorithm was chosen for the pressure-velocity coupling method. When the iterative residuals of the governing equations are less than $10^{-5}$ and the monitoring values of the area-weighted average temperature at the outlet and area- weighted average pressure at the inlet are stable, the numerical simulation is considered convergent.

The number of meshes is different for the four types of simulation domain due to the different geometries. However, the density of the mesh number (total number over domain volume) is quite close with the identical generation method. The predicted heat convection coefficients were calculated at $Q_{w}=-12 \mathrm{~kW} / \mathrm{m}^{2}, \quad G=200 \mathrm{~kg} / \mathrm{m}^{2}-\mathrm{s}$, and $P=8 \mathrm{MPa}$ for various bulk temperatures using three sets of meshes, 162981 cells, 396408 cells, and 566979 cells, with the rectangle cross section channel type to check mesh independency. Table 1 shows the mean deviation of the heat convection coefficient of all calculated points in Figure 4, and the relative error of the prediction data between case 2 and case 3 is quite small. Considering the computational cost and time, 400,000 mesh number is used as the baseline for the rest of the studies.

2.2. Verification with Experimental Data. To verify the accuracy of the numerical simulation, the results of the numerical simulation are compared with the experimental data in [22] for the cooling condition and with the experimental data in [23] for the heating condition. The physical model and boundary conditions of the simulation are consistent with the experiment shown in Figure 5. As Figure 5(a) shows, the CFD data and experimental data maintain a good consistency when the bulk temperature is far away from $T_{m}$, while as $T_{b}$ nears $T_{m}$, the deviation increases. The maximum heat transfer coefficient value of CFD data is also $3 \%$ larger than the experimental result, and the $T_{b}$ corresponding to this value deviates from the experimental data by $0.6^{\circ} \mathrm{C}$. For the heating condition, the experimental cases have the same $T_{\text {in }}=274 \mathrm{~K}, \quad Q_{w}=21 \mathrm{~kW} / \mathrm{m}^{2}$, and $P_{\text {out }}=13.1 \mathrm{MPa}$, but the different mass flux varies from 250 to $900 \mathrm{~kg} / \mathrm{m}^{2}-\mathrm{s}$. These experimental points do not cover the pseudocritical point, but cover a large range of mass flux. As shown in Figure 5(b), the CFD results are in good agreement with the experimental data, and the relative errors are less than $10 \%$. The comparison results show that the SST $\mathrm{k}$-omega model has the adequate accuracy to reproduce the experiments, and this conclusion is also obtained in [11].

\section{Results and Discussion}

3.1. Performance Parameters. The hydraulic diameter, $d_{h}$, was defined as follows:

$$
d_{h}=\frac{4 A}{C_{\text {wet }}},
$$

where $A$ is the channel cross-sectional area and $C_{\text {wet }}$ is the channel wet circumference.

The average convective heat convection coefficient $\alpha$ and channel pressure drop $\Delta P$ were defined as follows:

$$
\begin{gathered}
\alpha=\frac{Q_{w}}{T_{w}-T_{b}}, \\
\Delta P=P_{\text {in }}-P_{\text {out }},
\end{gathered}
$$




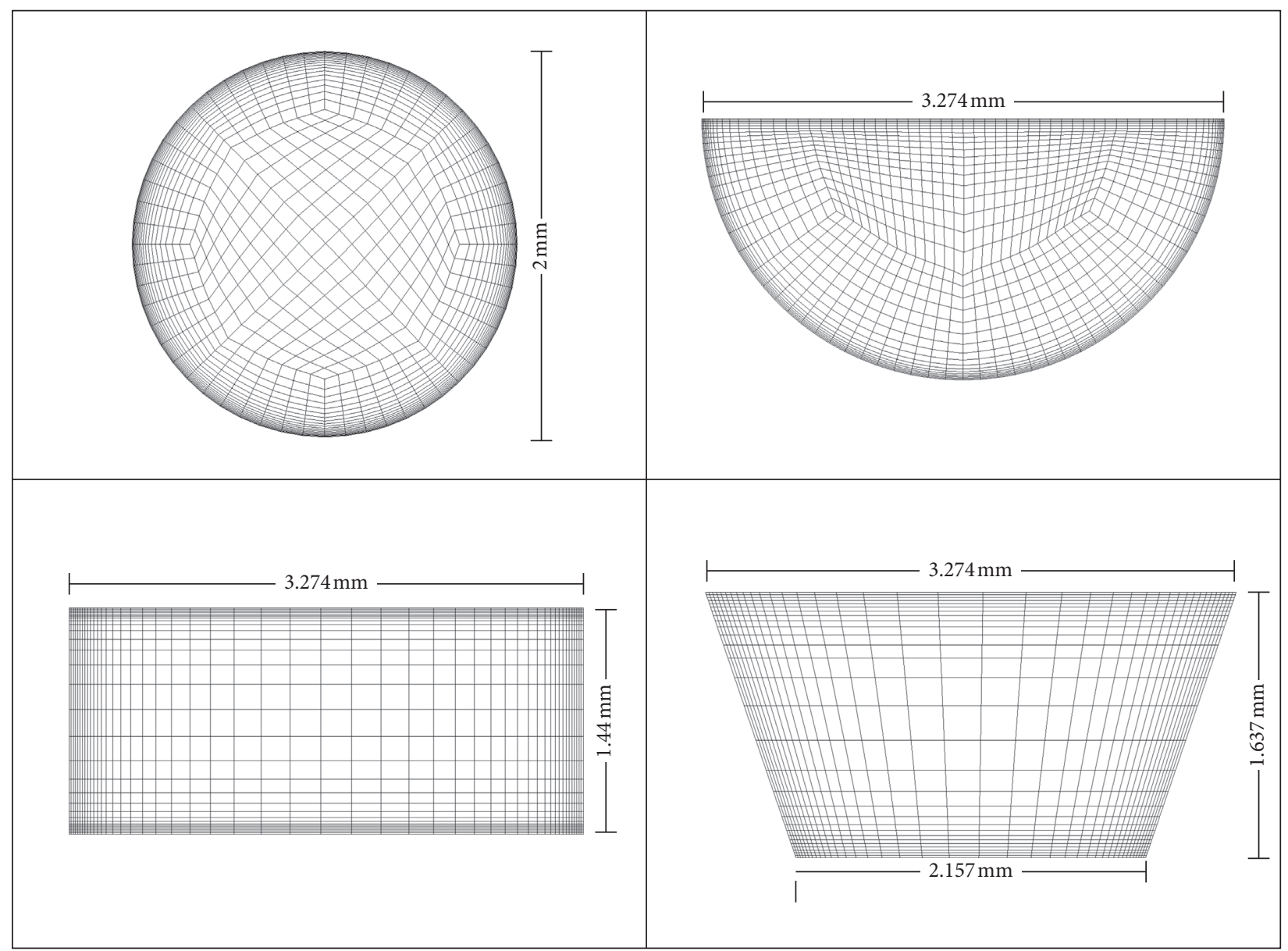

Figure 2: Mesh model and geometric size of the cross section.

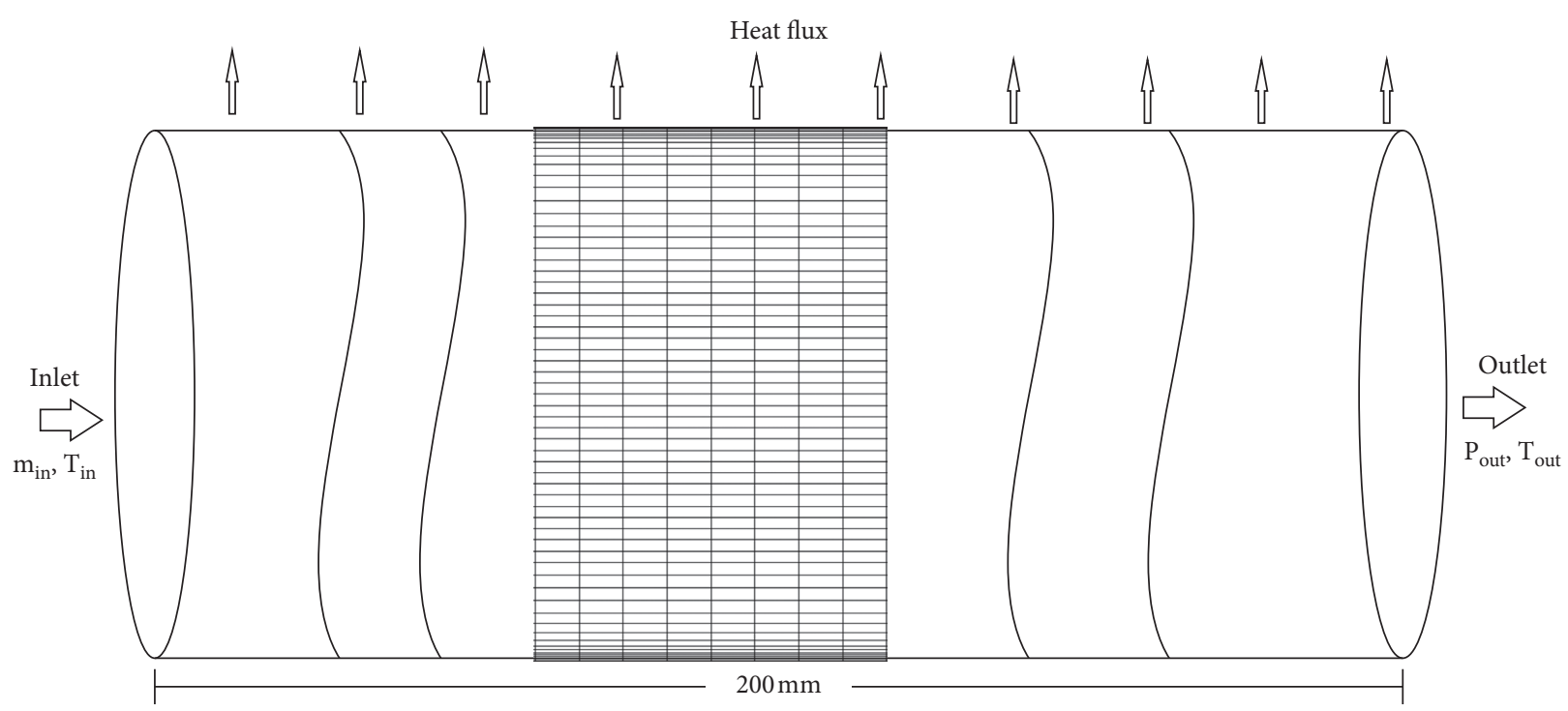

Figure 3: Physical model. 
TABLE 1: Mesh independency study.

\begin{tabular}{lcc}
\hline Cases & Number of cells & Mean deviation from case 3 (\%) \\
\hline Case 1 & 162981 & 13.76 \\
Case 2 & 396408 & 0.7 \\
Case 3 & 566979 & 0 \\
\hline
\end{tabular}

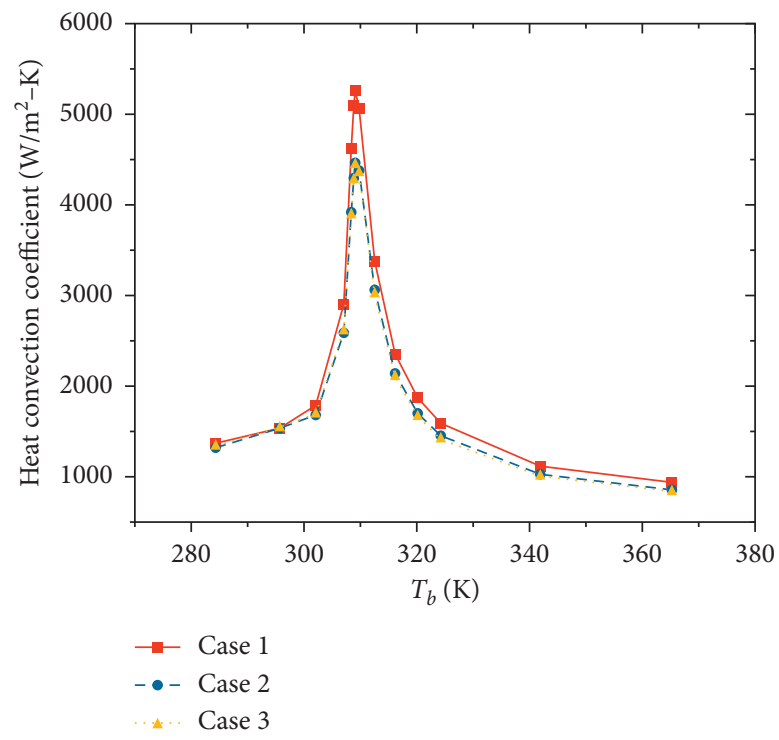

Figure 4: Comparison of the calculated heat convection coefficient of different meshes.

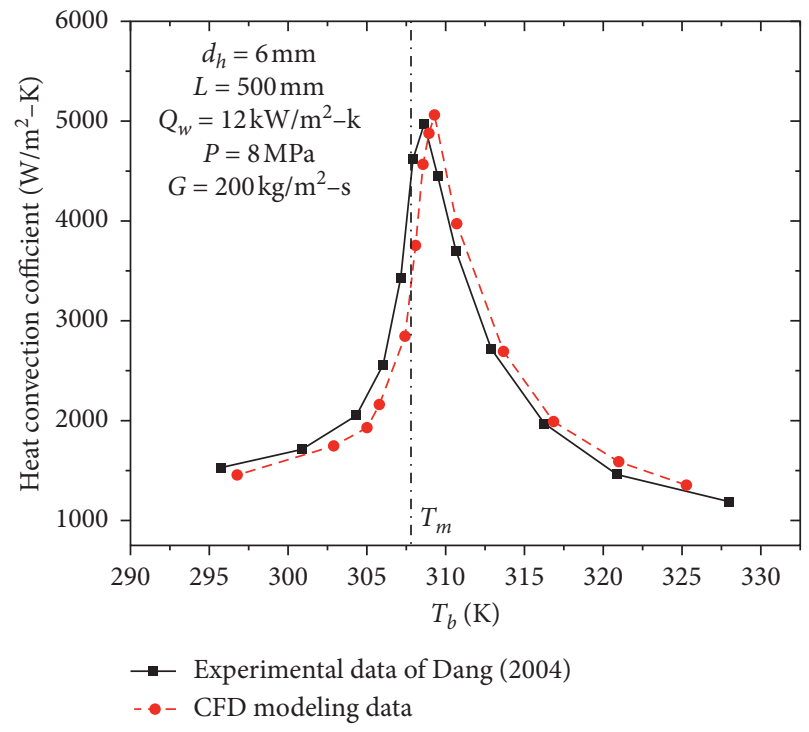

(a)

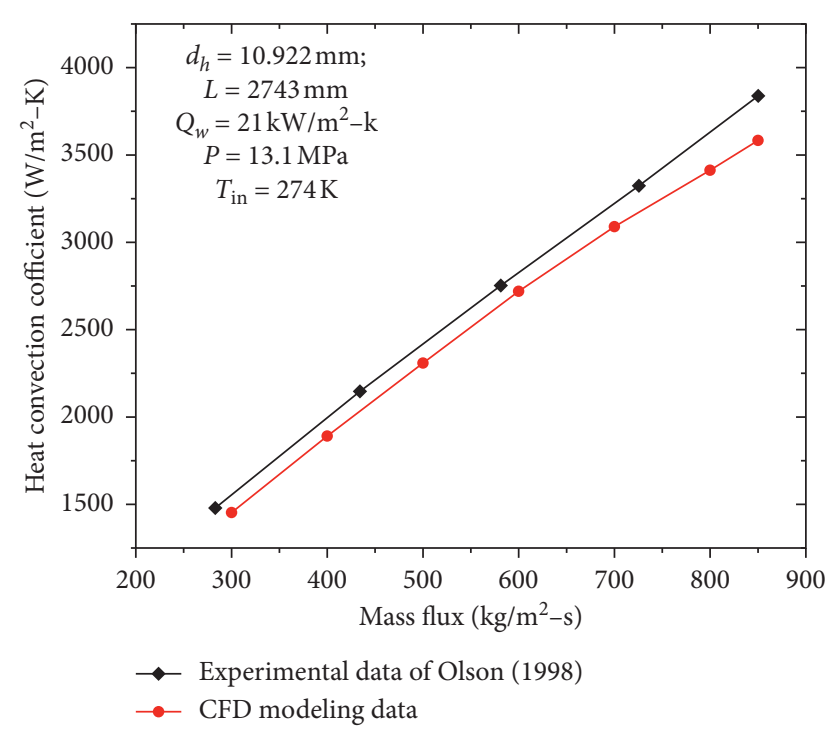

(b)

Figure 5: Verification with experimental data: (a) cooling condition; (b) heating condition.

where $Q_{w}$ is the wall heat flux with the positive value for heating and negative for the cooling case, $T_{w}$ is the wall average temperature, $T_{b}$ is the fluid area-weighted average bulk temperature, and $P_{\text {in }}$ and $P_{\text {out }}$ are the area-weighted average pressure of the inlet and outlet surface.
To understand the flow and heat transfer performance of other cross section types compared to the circular channel section more clearly, the heat convection coefficient and pressure drop are also expressed in the form of heat transfer enhancement ratio $e_{\alpha}$ and pressure drop enhancement ratio $e_{\Delta P}$ as follows: 


$$
\begin{gathered}
e_{\alpha}=\frac{\alpha_{\text {other-shaped }}}{\alpha_{\text {circular }}}, \\
e_{\Delta P}=\frac{\Delta P_{\text {other-shaped }}}{\Delta P_{\text {circular }}} .
\end{gathered}
$$

3.2. Numerical Results and Discussion. Numerical simulations are performed based on the numerical method in Section 2 . The average heat convection coefficient $\alpha$, channel total pressure drop $\Delta P$, heat convection coefficient enhancement ratio $e_{\alpha}$, and pressure drop enhancement ratio $e_{\Delta P}$ are obtained using the data reduction method in Section 3.1. Comparative numerical simulations are carried out under the same boundary conditions for four different cross section shaped channels. The simulated cases are listed in Table 2.

Figure 6 provides the $\alpha$ and $\Delta P$ results for the four types of channels at $G=200 \mathrm{~kg} / \mathrm{m}^{2}-\mathrm{s}, \quad P_{\text {out }}=8 \mathrm{MPa}, \quad$ and $Q_{w}= \pm 12 \mathrm{~kW} / \mathrm{m}^{2}$ in both heating and cooling conditions, and the bulk temperature range $T_{b}$ is from $280 \mathrm{~K}$ to $360 \mathrm{~K}$. It can be seen from this figure that a similar trend is observed for all channel cross section shapes studied for both $\alpha$ and $\Delta P$. The $\alpha$ of the four cross section shapes all rise sharply and reach the maximum value near the critical point. As $T_{b}$ runs away from the critical point, $\alpha$ decreases gradually and tends to be stable.

The maximum heat convection coefficient does not occur at the critical point, especially for cooling conditions as Figure 6 shows. This is mainly due to the thermosphysical properties of the fluids near the wall, which are determined by the local wall temperature, $T_{w}$, which also significantly affect the heat transfer in addition to the bulk fluid thermosphysical properties determined by $T_{b}$. In the heating case, $T_{w}>T_{b}$, while in the cooling case, $T_{w}<T_{b}$; however, whether $T_{w}$ is higher or lower than $T_{b}$, the specific heat and thermal conductivity of the $\mathrm{CO}_{2}$ fluid near the wall will both be smaller than the values at the critical point. As a result, the maximum heat convection coefficient will not occur at the pseudocritical point for both cases.

As for the cooling case, the maximum of $\alpha$ occurs at the location where $T_{b}$ is slightly higher than $T_{m}$ while $T_{w}$ is slightly lower than $T_{m}$ which is consistent with the conclusion of $[14,24]$, while the deviation of the heating case is relatively smaller than that of the cooling case as Figure 6 shows. This is because the influence of $T_{w}$ on the thermal properties near the wall is multifaceted. As for the heating case, $T_{w}>T_{b}$, the viscosity of the fluid near the wall decreases, the thickness of the viscous sublayer will also decrease, and this is beneficial to the heat transfer enhancement. While the fluid thermal conductivity also decreases as the temperature rises at the wall area except for the very narrow range near the critical point where the variation trend depends on the relationship between $T_{b}$ and $T_{m}$, this will lead to the weakening of the heat transfer effect. These influences are completely opposite for the cooling case. The comprehensive influence can be seen in Figure 6, under the same inlet $G_{\text {in }}, P_{\text {out }}, T_{b}$, and absolute value $Q_{w}$, and the $\alpha$ of cooling cases is significantly greater than that of heating cases.
As shown in the comparative results, the four types of cross section channels listed in descending order of heat transfer performance are the circular channel, semicircular channel, rectangle channel, and trapezoid channel. The results of pressure drop show that the circular channel will also bring the maximum pressure drop as it has the best heat transfer performance in the four cross section types. To express the influence of channel shapes on flow and heat transfer performance more clearly, Figure 7 provides the analysis results of $e_{\alpha}$ and $e_{p}$ defined in Section 3.1 under different boundary conditions. As shown in Figure 7, the effect of the channel cross section type on $\alpha$ is greater than that on $\Delta P$, especially near the pseudocritical point. For the trapezoidal channel, the convective heat convection coefficient at the critical point is reduced to about $42 \%$ of the circular channel value in the heating condition and $65 \%$ in cooling condition. It is a significant impact. The influence of channel cross section shape on the pressure drop is relatively small. The pressure drops of all channel types are higher than $85 \%$ of the circular channel section for both cooling and heating conditions.

Figure 8 shows the velocity contours of the channel cross section for the four channel types. As shown in this figure, the corner area has an obvious blocking effect on the nearby fluid, especially for acute angles, and the velocity of the fluid around the corner area decreases, which makes the heat transfer intensity in the corner region significantly weaker than that in the noncorner region. Obviously, it is because of the existence of acute angles that the trapezoidal section has the worst heat transfer performance among the four cross section forms.

The comparisons of the four types of cross section channels are based on the same hydraulic diameter, which is defined as $4 A / C_{\text {wet }}$. The total heat transfer area of the channel depends on the wet circumference under the same channel length. Therefore, the abovementioned four channel types provide the same heat transfer area per unit cross-sectional area at the same hydraulic diameter. This means that the total heat transfer area of a single plate of PCHE with different types of channels only depends on the section area utilization. Therefore, if the same total cross-sectional area channels are arranged on the heat exchanger plates of the same size, the heat transfer performance sequencing from high to low is still circular, semicircular, rectangle, and trapezoidal.

3.3. Comparison with Correlative Models. A lot of correlations were developed for forced convective heat transfer in the supercritical region. Based on the research conclusion of [25], the forced convective heat transfer of fluids in the nearcritical region could be predicted by Dittus-Boelter-type heat transfer correlations while using the property ratio method to account for large variations of physical properties in the near-critical region. Also, the correlation given by Jackson was the most accurate one [26]. The correlation is described as follows:

$$
N u=0.0183 \operatorname{Re}_{b}^{0.82} \operatorname{Pr}_{b}^{0.5}\left(\frac{\rho_{w}}{\rho_{b}}\right)^{0.3}\left(\frac{\overline{C_{P}}}{C_{p b}}\right)^{n}
$$


TABLe 2: Simulated cases.

\begin{tabular}{|c|c|c|c|c|c|}
\hline No. & $G\left(\mathrm{~kg} / \mathrm{m}^{2}-\mathrm{s}\right)$ & $T_{\text {in }}(\mathrm{K})$ & $P_{\text {out }}(\mathrm{MPa})$ & $Q_{w}\left(\mathrm{~kW} / \mathrm{m}^{2}\right)$ & Cross section type \\
\hline 1 & 200 & 285 & 8 & $-12 / 12$ & Circular/semicircular/rectangle/trapezoid \\
\hline 2 & 200 & 290 & 8 & $-12 / 12$ & Circular/semicircular/rectangle/trapezoid \\
\hline 3 & 200 & 300 & 8 & $-12 / 12$ & Circular/semicircular/rectangle/trapezoid \\
\hline 4 & 200 & 305 & 8 & $-12 / 12$ & Circular/semicircular/rectangle/trapezoid \\
\hline 5 & 200 & 306 & 8 & 12 & Circular/semicircular/rectangle/trapezoid \\
\hline 6 & 200 & 307 & 8 & 12 & Circular/semicircular/rectangle/trapezoid \\
\hline 7 & 200 & 307.5 & 8 & 12 & Circular/semicircular/rectangle/trapezoid \\
\hline 8 & 200 & 308 & 8 & $-12 / 12$ & Circular/semicircular/rectangle/trapezoid \\
\hline 9 & 200 & 309 & 8 & $-12 / 12$ & Circular/semicircular/rectangle/trapezoid \\
\hline 10 & 200 & 309.5 & 8 & -12 & Circular/semicircular/rectangle/trapezoid \\
\hline 11 & 200 & 310 & 8 & $-12 / 12$ & Circular/semicircular/rectangle/trapezoid \\
\hline 12 & 200 & 311 & 8 & -12 & Circular/semicircular/rectangle/trapezoid \\
\hline 13 & 200 & 315 & 8 & $-12 / 12$ & Circular/semicircular/rectangle/trapezoid \\
\hline 14 & 200 & 320 & 8 & $-12 / 12$ & Circular/semicircular/rectangle/trapezoid \\
\hline 15 & 200 & 325 & 8 & $-12 / 12$ & Circular/semicircular/rectangle/trapezoid \\
\hline 16 & 200 & 330 & 8 & $-12 / 12$ & Circular/semicircular/rectangle/trapezoid \\
\hline 17 & 200 & 350 & 8 & $-12 / 12$ & Circular/semicircular/rectangle/trapezoid \\
\hline 18 & 200 & 375 & 8 & -12 & Circular/semicircular/rectangle/trapezoid \\
\hline
\end{tabular}

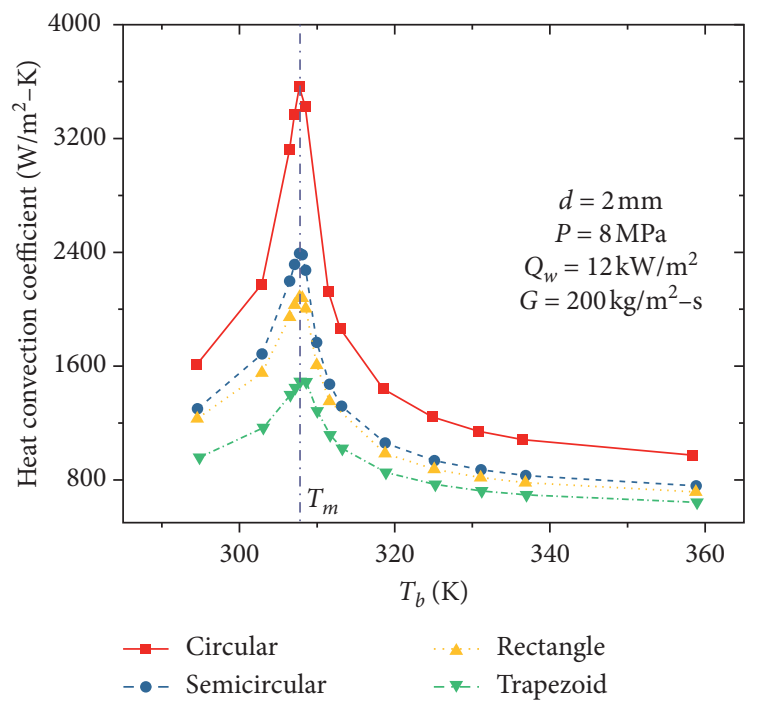

(a)

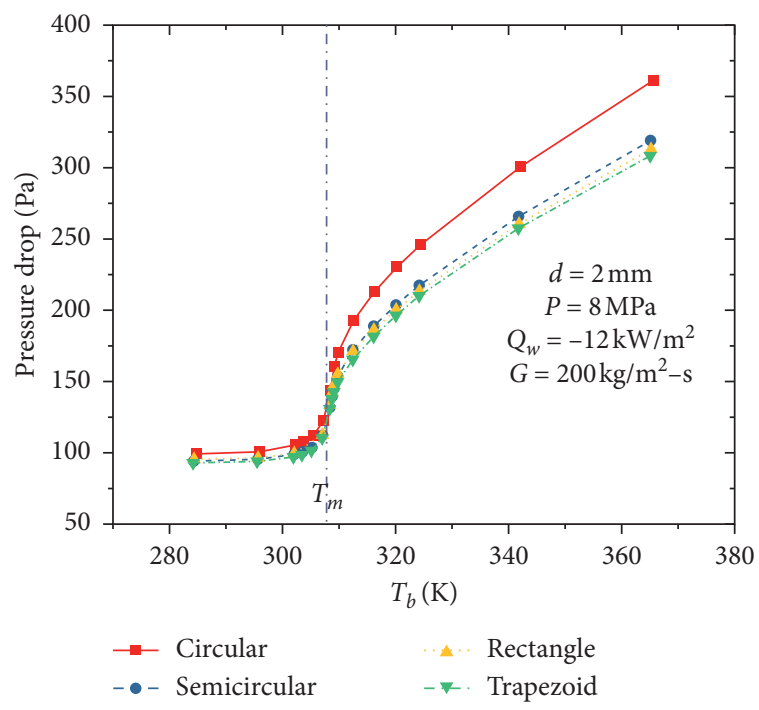

(b)

Figure 6: Continued. 


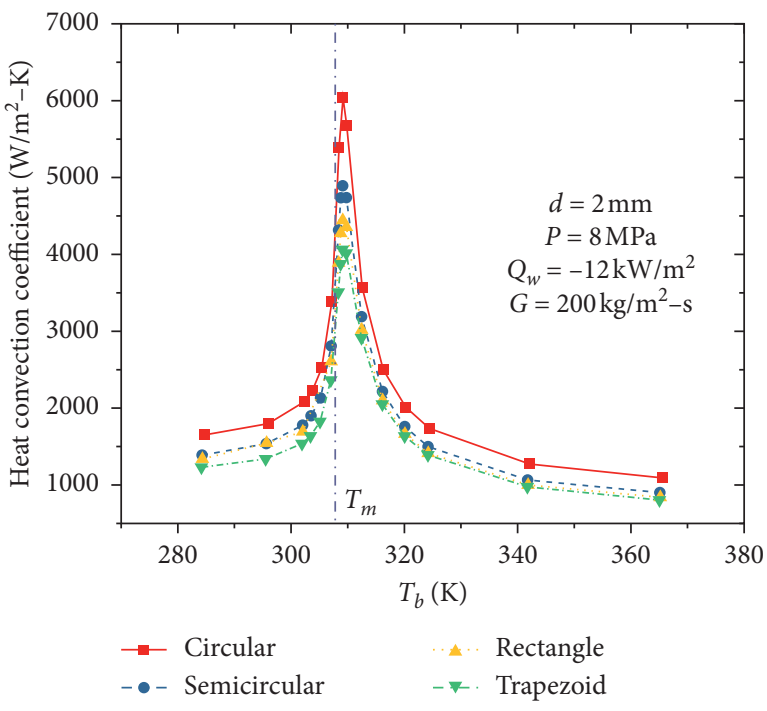

(c)

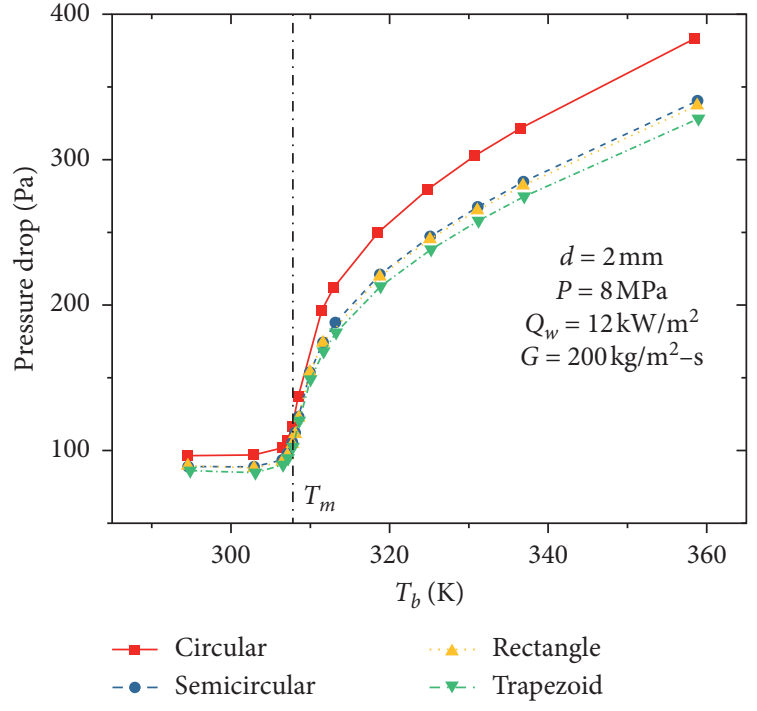

(d)

Figure 6: Heat convection coefficient and pressure drop results: (a) $\alpha$ of the heating case; (b) $\Delta P$ of the heating case; (c) $\alpha$ of the cooling case; and (d) $\Delta P$ of the cooling case.

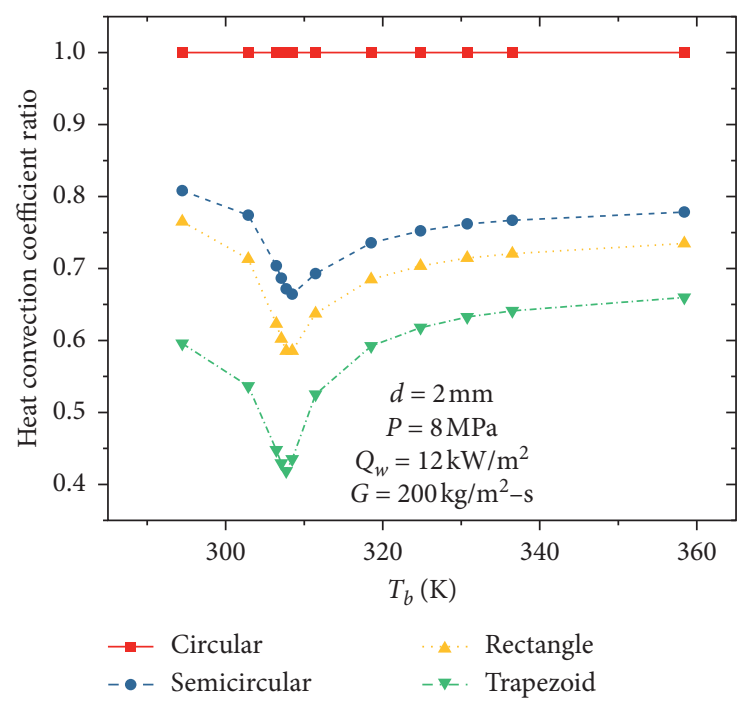

(a)

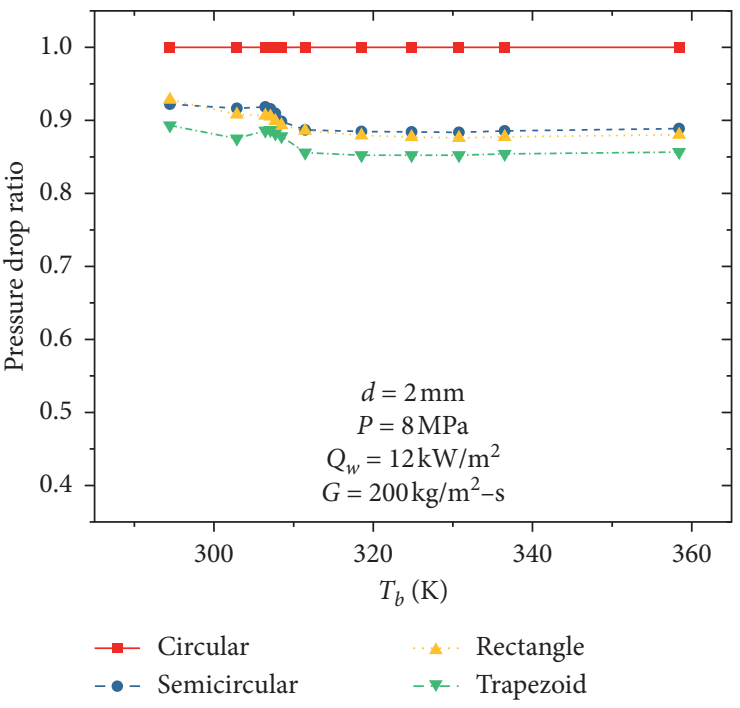

(b)

Figure 7: Continued. 


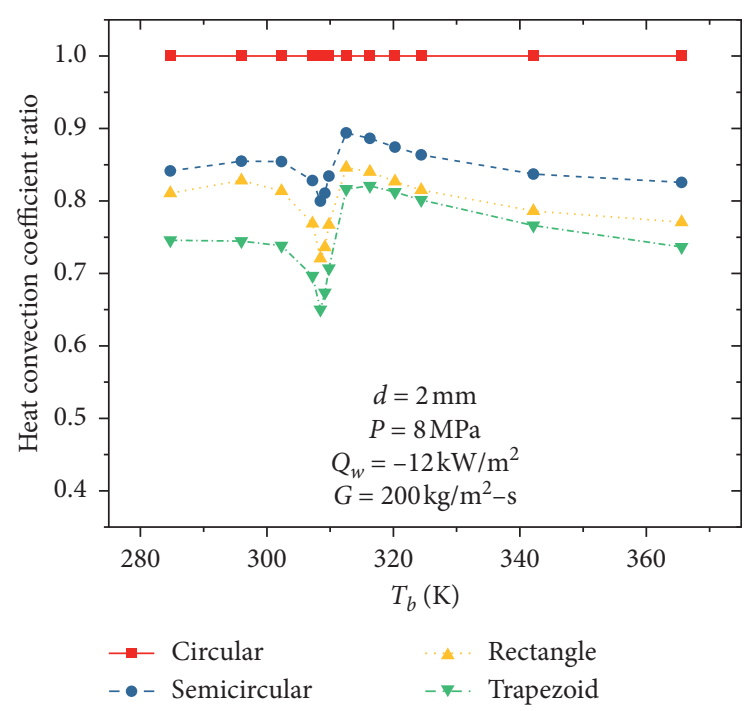

(c)

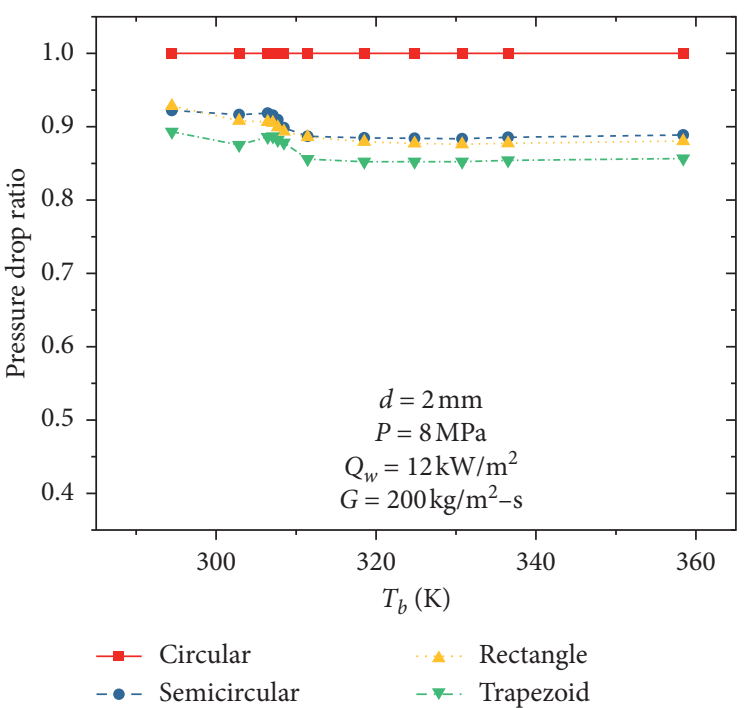

(d)

Figure 7: Heat convection coefficient and pressure drop enhancement ratio results: (a) $e_{\alpha}$ of the heating case; (b) $e_{\Delta P}$ of the heating case; (c) $e_{\alpha}$ of the cooling case; and (d) $e_{\Delta P}$ of the cooling case.

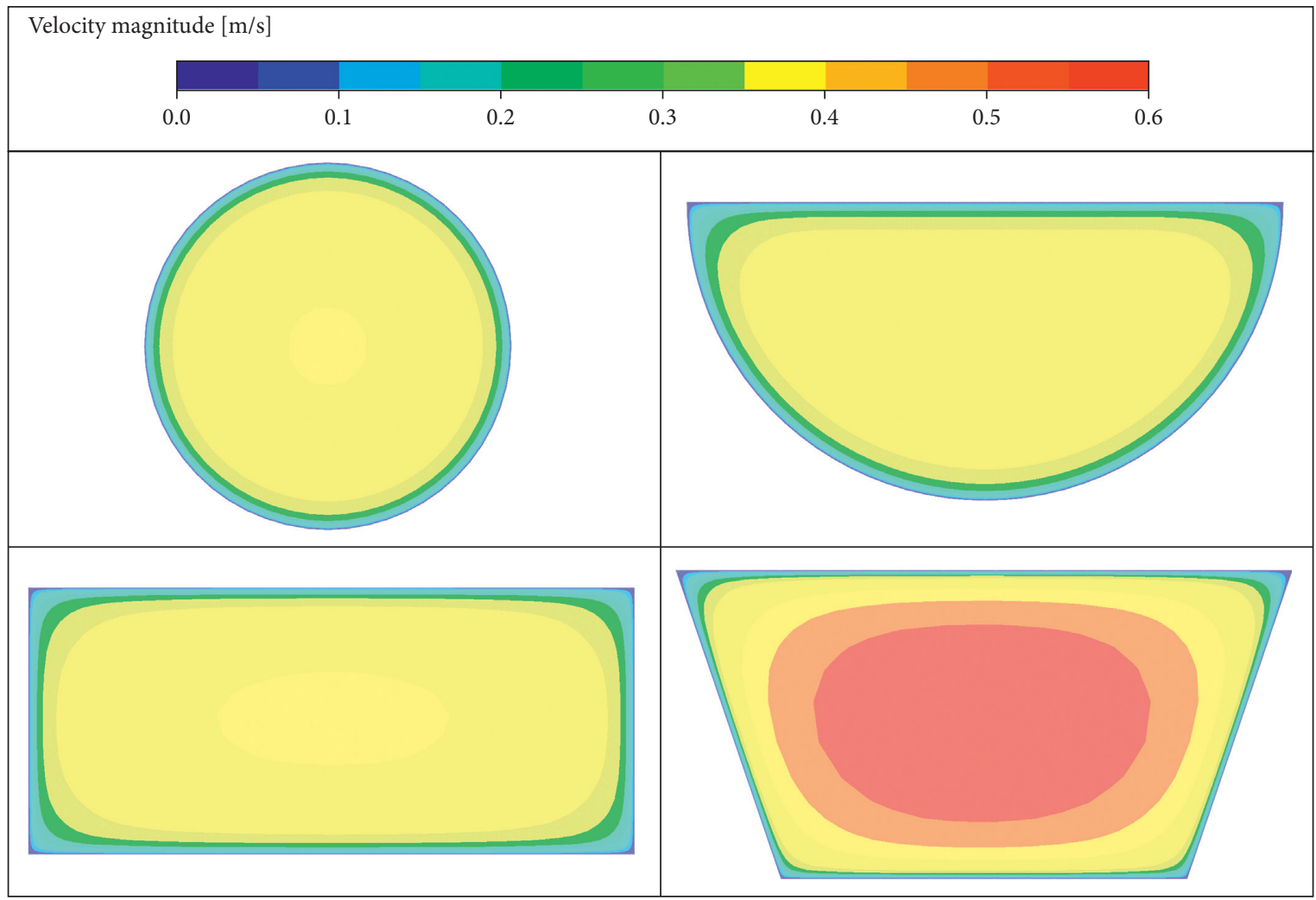

FIGURE 8: Velocity contours of the channel cross section. 


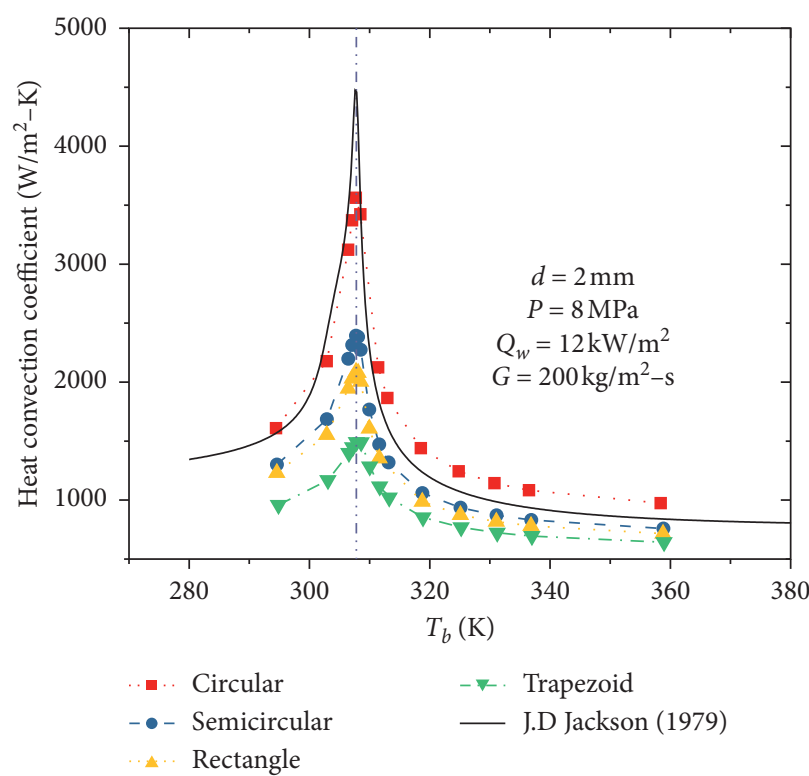

(a)

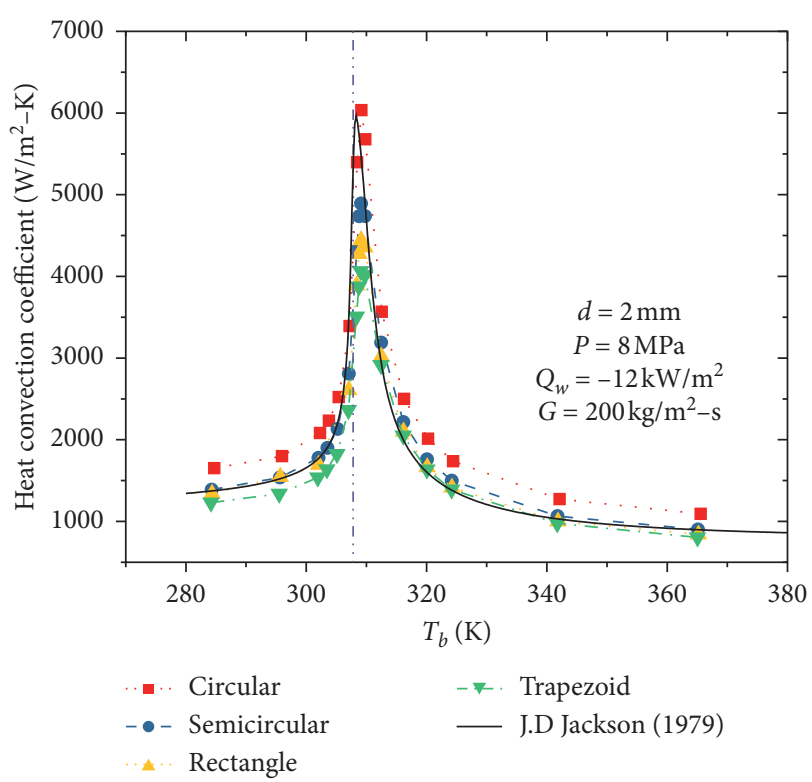

(b)

Figure 9: Comparison of simulated data with the calculated heat convection coefficients using Jackson correlation as a function of $T_{b}$ : (a) heating case; (b) cooling case.

where

$$
\begin{aligned}
& \overline{C_{P}}=\frac{i_{b}-i_{w}}{T_{b}-T_{w}}, \\
& n= \begin{cases}0.4, & \text { when } T_{b}<T_{w}<T_{m} \text { or } 1.2 T_{m}<T_{b}<T_{w} \\
0.4+0.2\left(\frac{T_{w}}{T_{m}}-1\right), & \text { when } T_{b}<T_{m}<T_{w}, \\
0.4+0.2\left(\frac{T_{w}}{T_{m}}-1\right)\left[1-5\left(\frac{T_{b}}{T_{m}}-1\right)\right], & \text { when } T_{m}<T_{b}<1.2 T_{m}, \text { and } T_{b}<T_{w} .\end{cases}
\end{aligned}
$$

Based on MATLAB/Simulink software and the NIST database, the analysis model of Jackson correlation is established. The results are compared with CFD analysis data for the 4 types of cross section channels as Figure 9 shows. It can be seen that the results of the CFD simulations agree considerably well with Jackson correlation under all present working conditions either in the heating or cooling mode for the circular channel. However, the errors between CFD and Jackson correlation results of the other three channel types increase significantly, especially near the pseudocritical region.

Figure 10 shows the relative error between CFD and Jackson correlation calculation results for these 4 types of channels under heating condition. The relative error is defined as Err $=\left(\alpha_{\text {Jackson }}-\alpha_{\mathrm{CFD}}\right) / \alpha_{\mathrm{CFD}}$. As Figure 10(a) shows, the relative errors are less than $25.4 \%$ for all simulation cases of the circular channel, which indicates that the Jackson formula can well predict the convective heat convection coefficient of the circular channel in the heating mode, while for the other 3 types of channels, the calculation error of Jackson correlation increases significantly, especially when $T_{b}$ is close to $T_{m}$. As the relative error results shown in Figures $10(\mathrm{~b})-10(\mathrm{~d})$, Jackson correlation is not suitable for predicting the heat convection coefficient of noncircular channels, especially when the fluid is close to the pseudocritical state.

For the cooling condition, as shown in Figure 11, the prediction error of Jackson correlation for heat convection coefficient is less than that of the heating condition, and Jackson correlation provides adequate accuracy for all studied cases of the circular channel which cover the pseudocritical point. However, for the other three types of 


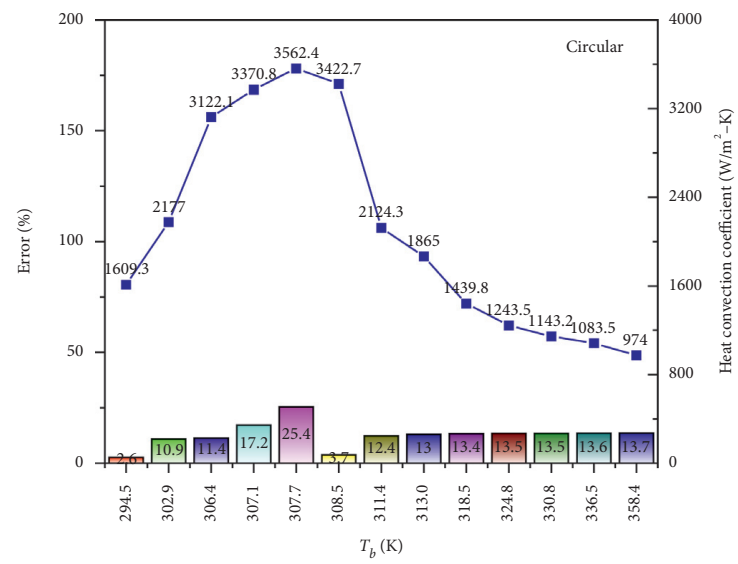

(a)

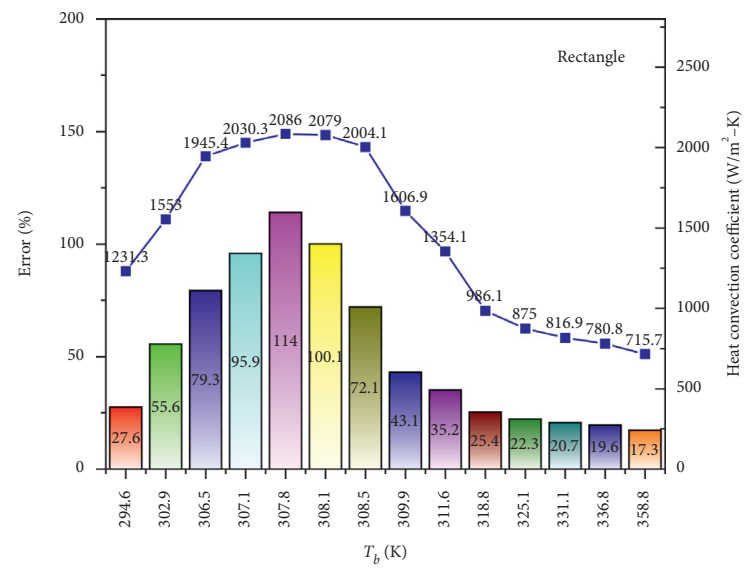

(c)

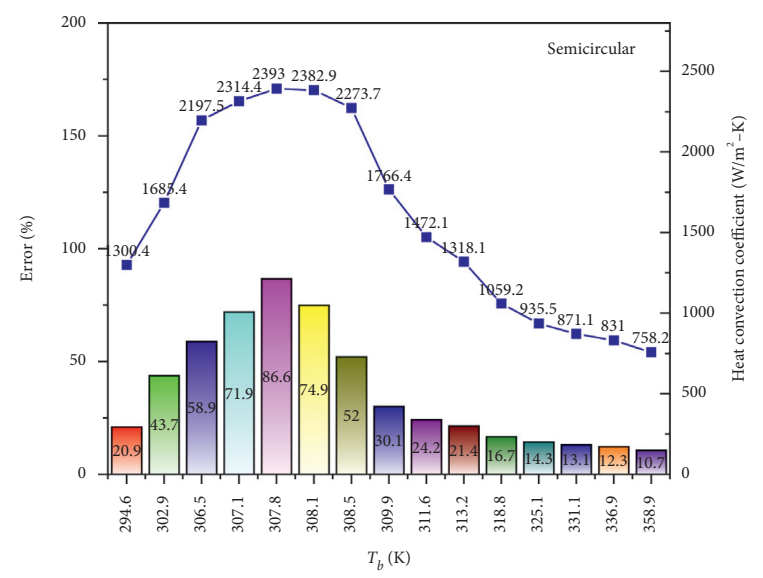

(b)

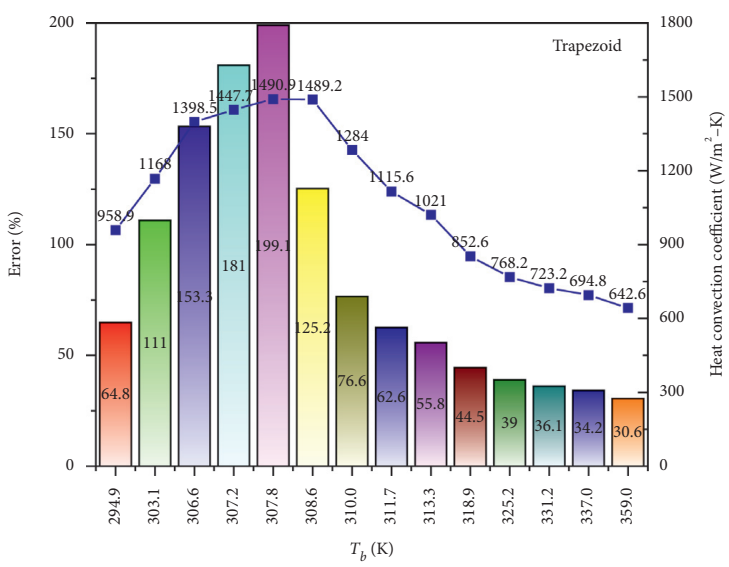

(d)

FIGURE 10: The relative error between CFD and Jackson correlation analysis results for the heating mode: (a) circular; (b) semicircular; (c) rectangle; and (d) trapezoid.

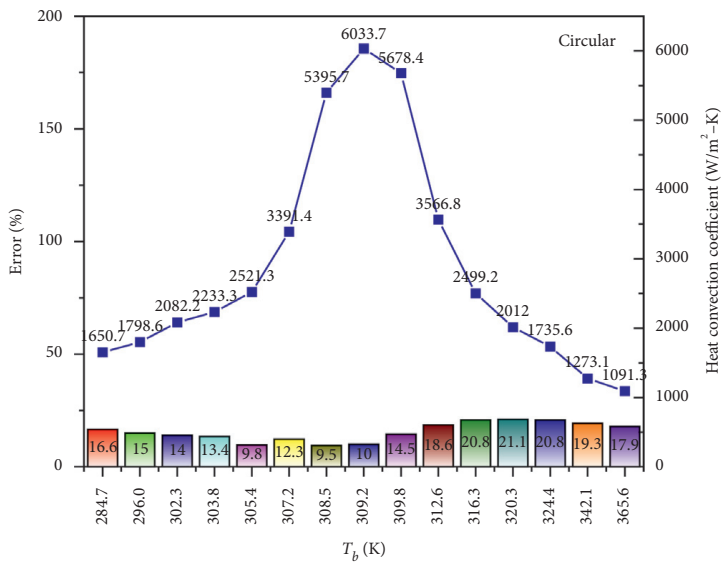

(a)

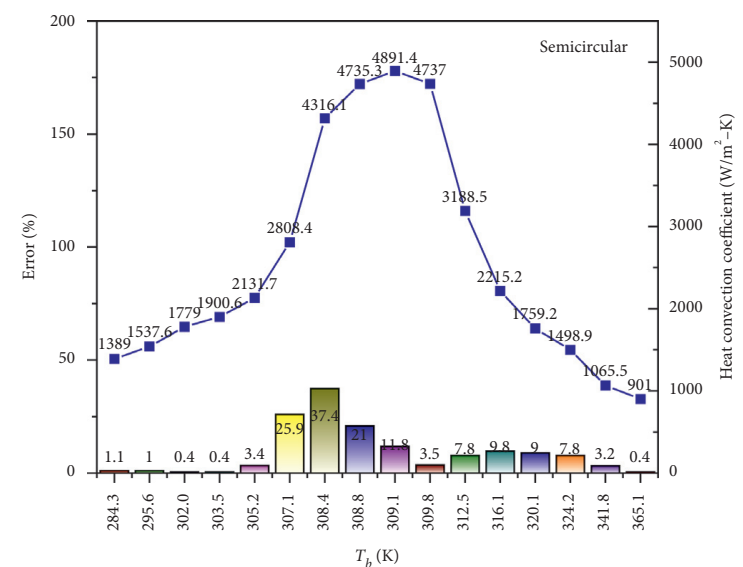

(b)

Figure 11: Continued. 


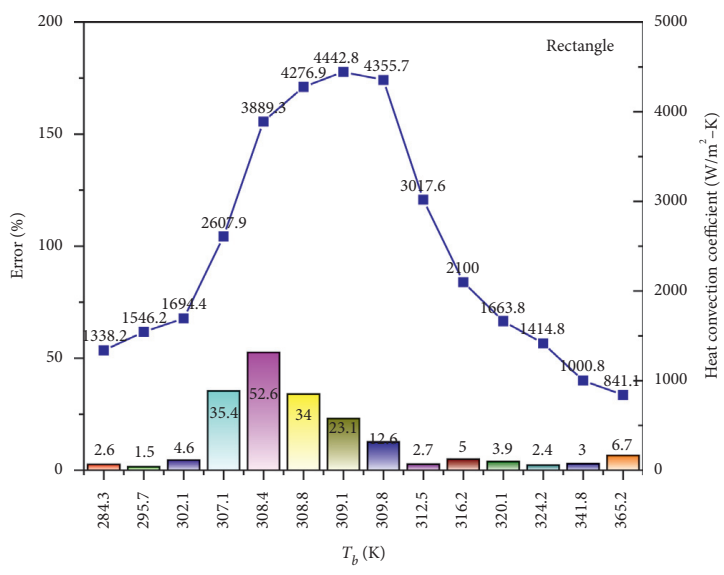

(c)

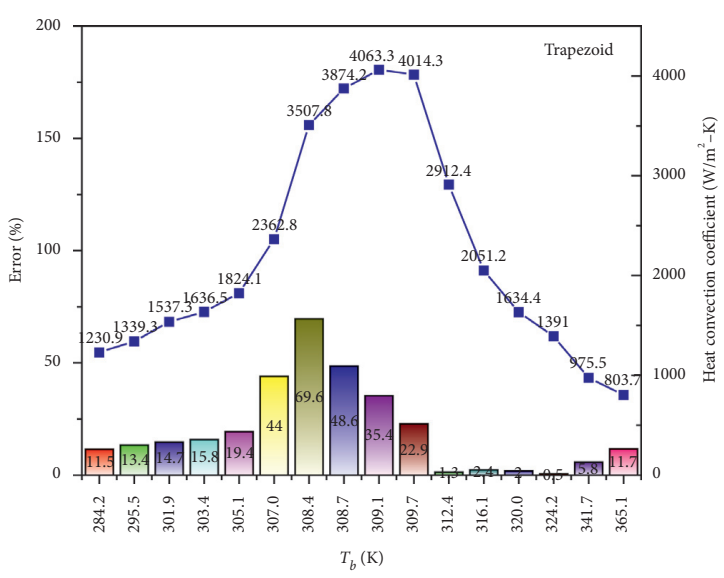

(d)

FIGURE 11: The relative error between CFD and Jackson correlation analysis results for the cooling mode: (a) circular; (b) semicircular; (c) rectangle; and (d) trapezoid.

channels, the relative error will still gradually increase when $T_{b}$ is close to $T_{m}$, which means that Jackson is still unable to predict the heat convention coefficient accurately.

As to the $\mathrm{CO}_{2}$ fluid, when it is close to the pseudocritical state, the dramatic changes of the fluid thermal physical properties have a significant influence on its heat transfer performance, and this also leads to the influence of the channel cross section shape on the heat transfer performance increasing. The traditional correlations of the circular channel are no longer applicable, and more special research is suggested to be conducted with the consideration of the channel geometry parameters to get the modification method of the predictive correlation.

\section{Conclusions}

A comparative study of the thermal-hydraulic performance of $\mathrm{SCO}_{2}$ in four different channel cross section types was conducted with the numerical method for a wide range of fluid bulk temperature which covers the critical point. The results show that

(1) The sequencing of heat transfer performance from high to low of horizontal microchannels with $\mathrm{SCO}_{2}$ fluid is the circular channel, semicircular channel, rectangle channel, and trapezoid channel under the same hydraulic diameter and boundary conditions, while the sequencing of pressure drop is also in the same order

(2) The effect of cross section shape on the pressure drop of the channel fluid is significantly less than that on the heat convection coefficient of the $\mathrm{SCO}_{2}$ channel

(3) The existence of the corner region of the channel cross section, especially the acute angle, has a significant impact on the channel heat transfer performance, which should be avoided in the design of channel cross section

\section{Nomenclature}

A: Cross-sectional area $\left(\mathrm{m}^{2}\right)$

C: Circumference $(\mathrm{m})$

$C_{p}:$ Specific heat $(\mathrm{J} / \mathrm{kg}-\mathrm{K})$

$d: \quad$ Diameter $(\mathrm{m})$

$e$ : Enhancement ratio

Err: Relative error

G: Mass flux $\left(\mathrm{kg} / \mathrm{m}^{2}-\mathrm{s}\right)$

$i: \quad$ Specific enthalpy $(\mathrm{J} / \mathrm{kg})$

$\mathrm{Nu}$ : Nusselt number

$P$ : $\quad$ Pressure $(\mathrm{Pa})$

Pr: Prandtl number

Q: Heat flux $\left(\mathrm{W} / \mathrm{m}^{2}\right)$

Re: Reynolds number

T: $\quad$ Temperature $(\mathrm{K})$

$\alpha: \quad$ Heat convection coefficient $\left(\mathrm{W} / \mathrm{m}^{2}-\mathrm{K}\right)$

$\rho: \quad$ Density $\left(\mathrm{kg} / \mathrm{m}^{3}\right)$

$\Delta P$ : Pressure drop $(\mathrm{Pa})$.

\section{Subscripts}
b: Bulk
$h$ : Hydraulic
in: Inlet
$m$ : Pseudocritical
out: Outlet
$w$ : Wall.

\section{Data Availability}

All underlying data are contained in the uploaded manuscript.

\section{Conflicts of Interest}

The authors declare no conflicts of interest. 


\section{Acknowledgments}

This project was supported by the fund of the Natural Science Project of Hunan Province, China, with the item no. 2020JJ5393 and the Education Department of Hunan Province, China, with the item no. $18 \mathrm{C} 0735$.

\section{References}

[1] Q. Li, G. Flamant, X. Yuan, P. Neveu, and L. Luo, "Compact heat exchangers: a review and future applications for a new generation of high temperature solar receivers," Renewable and Sustainable Energy Reviews, vol. 15, no. 9, pp. 4855-4875, 2011.

[2] M. Chen, X. Sun, R. N. Christensen et al., "Experimental and numerical study of a printed circuit heat exchanger," Annals of Nuclear Energy, vol. 97, pp. 221-231, 2016.

[3] B. Halimi and K. Y. Suh, "Computational analysis of supercritical $\mathrm{CO}_{2}$ Brayton cycle power conversion system for fusion reactor," Energy Conversion and Management, vol. 63, pp. 38-43, 2012.

[4] T. H. Kim, J. G. Kwon, S. H. Yoon, H. S. Park, M. H. Kim, and J. E. Cha, "Numerical analysis of air-foil shaped fin performance in printed circuit heat exchanger in a supercritical carbon dioxide power cycle," Nuclear Engineering and Design, vol. 288, pp. 110-118, 2015.

[5] X. Xu, T. Ma, L. Li et al., "Optimization of fin arrangement and channel configuration in an airfoil fin PCHE for supercritical $\mathrm{CO}_{2}$ cycle," Applied Thermal Engineering, vol. 70, no. 1, pp. 867-875, 2014.

[6] R. Le Pierres, D. Southall, and S. Osborne, Impact of mechanical design issues on printed circuit heat exchangers, 2011, https://www.heatric.com/app/uploads/2018/04/Impactof-mechanical-design-issues-on-PCHE.pdf.

[7] K. Nikitin, Y. Kato, and L. Ngo, "Printed circuit heat exchanger thermal-hydraulic performance in supercritical CO2 experimental loop," International Journal of Refrigeration, vol. 29 , no. 5, pp. 807-814, 2006.

[8] T. L. Ngo, Y. Kato, K. Nikitin, and T. Ishizuka, "Heat transfer and pressure drop correlations of microchannel heat exchangers with S-shaped and zigzag fins for carbon dioxide cycles," Experimental Thermal and Fluid Science, vol. 32, no. 2, pp. 560-570, 2007.

[9] H. A. Mohammed, P. Gunnasegaran, and N. H. Shuaib, "Influence of channel shape on the thermal and hydraulic performance of microchannel heat sink," International Communications in Heat and Mass Transfer, vol. 38, no. 4, pp. 474-480, 2011.

[10] A. Kruizenga, H. Li, M. Anderson, and M. Corradini, "Supercritical carbon dioxide heat transfer in horizontal semicircular channels," Journal of Heat Transfer, vol. 134, no. 8, 2012.

[11] H. Li, Y. Zhang, L. Zhang, M. Yao, A. Kruizenga, and M. Anderson, "PDF-based modeling on the turbulent convection heat transfer of supercritical $\mathrm{CO}_{2}$ in the printed circuit heat exchangers for the supercritical $\mathrm{CO}_{2}$ Brayton cycle," International Journal of Heat and Mass Transfer, vol. 98, pp. 204-218, 2016.

[12] S.-M. Lee and K.-Y. Kim, "Comparative study on performance of a zigzag printed circuit heat exchanger with various channel shapes and configurations," Heat and Mass Transfer, vol. 49, no. 7, pp. 1021-1028, 2013.

[13] Y.-J. Baik, S. Jeon, B. Kim, D. Jeon, and C. Byon, "Heat transfer performance of wavy-channeled PCHEs and the effects of waviness factors," International Journal of Heat and Mass Transfer, vol. 114, pp. 809-815, 2017.

[14] Z. Ren, C. R. Zhao, P. X. Jiang, and H. L. Bo, "Investigation on local convection heat transfer of supercritical CO2 during cooling in horizontal semicircular channels of printed circuit heat exchanger," Applied Thermal Engineering, vol. 157, Article ID 113697, 2019.

[15] Y. Tu and Y. Zeng, "Flow and heat transfer characteristics study of supercritical $\mathrm{CO}_{2}$ in horizontal semicircular channel for cooling process," Case Studies in Thermal Engineering, vol. 21, Article ID 100691, 2020.

[16] Y. Tu and Y. Zeng, "Heat transfer and hydraulic characteristics of supercritical $\mathrm{CO} 2$ in cooled and heated horizontal semicircular channels," Journal of Applied Fluid Mechanics, vol. 14, no. 5, pp. 1351-1362, 2021.

[17] L. M. Pua and S. O. Rumbold, "Industrial microchannel devices - where are we today?" International Conference on Microchannels and Minichannels, vol. 1, pp. 773-780, 2003.

[18] A. R. Pardakhti and M. Mejari, "Evaluation of the heat transfer rate increases in retention pools nuclear waste," International Journal of Nano Dimension; Tonekabon, vol. 6, no. 4, pp. 385-398, 2019.

[19] J. Alinejad and M. M. Peiravi, "Numerical analysis of secondary droplets characteristics due to drop impacting on 3D cylinders considering dynamic contact angle," Meccanica, vol. 55, no. 10, pp. 1975-2002, 2020.

[20] M. M. Peiravi, "Numerical study of fins arrangement and nanofluids effects on three-dimensional natural convection in the cubical enclosure," Transport Phenomena in Nano and Micro Scales, vol. 7, no. 2, pp. 97-112, 2019.

[21] M. M. Peiravi, J. Alinejad, D. D. Ganji, and S. Maddah, "3D optimization of baffle arrangement in a multi-phase nanofluid natural convection based on numerical simulation," International Journal of Numerical Methods for Heat and Fluid Flow, vol. 30, no. 5, pp. 2583-2605, 2020.

[22] C. Dang and E. Hihara, "In-tube cooling heat transfer of supercritical carbon dioxide. Part 2. Comparison of numerical calculation with different turbulence models," International Journal of Refrigeration, vol. 27, no. 7 SPEC. ISS., pp. 748-760, 2004.

[23] A. Douglas and D. A. Olson, "Heat transfer in turbulent supercritical carbon dioxide flowing in a heated horizontal tube," NIST, Gaithersburg, MD, USA, 1998.

[24] H. Li, A. Kruizenga, M. Anderson et al., "Development of a new forced convection heat transfer correlation for $\mathrm{CO} 2$ in both heating and cooling modes at supercritical pressures," International Journal of Thermal Sciences, vol. 50, no. 12, pp. 2430-2442, 2011.

[25] A. J. Ghajar and A. Asadi, "Improved forced convective heattransfer correlations for liquids inthe near-critical region," AIAA Journal, vol. 24, no. 12, pp. 2030-2037, 1986.

[26] S. S. Pitla, D. M. Robinson, E. A. Groll, and S. Ramadhyani, "Heat transfer from supercritical carbon dioxide in tube flow: a critical review," ASHRAE Transactions, vol. 105, no. May 2013, pp. 37-41, 1999. 